\title{
La suciedad del tiempo: Escenarios del fin del mundo en la narrativa anti-monumental de Teixeira Coelho Neto
}

\author{
A Pile of Debris: Doomsday Scenarios in Teixeira Coelho \\ Neto's Anti Monumental Narrative
}

\author{
LUZ HORNE \\ Universidad de San Andres, Departamento de Humanidades, Buenos Aires, Argentina. \\ Correo electrónico: lhorne@udesa.edu.ar
}

Este ensayo toma el ciclo de cuatro novelas del escritor y crítico de arte brasileño Teixeira Coelho Neto-Niemeyer, um romance (1994); Historia Natural da ditadura (2006), O homem que vive, uma jornada sentimental (2010) y Colosso (2015) - agrupado bajo el nombre de "el ángel de la historia" (Walter Benjamin), en el que se presenta una visión apocalíptica del fin del mundo entretejida con una reflexión sobre la vida, la política, el arte y la literatura. El ensayo sostiene que el imaginario catastrófico de las novelas se revela como estructuralmente ligado a un proyecto de modernización desarrollista e industrial (cuyo punto cúlmine está en la construcción de Brasilia), en los que la literatura y el arte se entienden desde una epistemología basada en la razón, la monumentalidad, el evolucionismo y la autonomía estética. Contrariamente, Coelho Neto se propone construir una escritura material, hecha con los escombros de una vida: una estética menor, de los "sin nombre", del deshecho y del derroche. La literatura contemporánea adquiere de esta manera una impronta casi filosófica, pues se transforma en un sitio de generación de conceptos; un sitio a partir del cual construir una teoría crítica de un modo ajeno al de la razón (monumental) moderna.

Palabras claves: Teixeira Coelho Neto, Brasilia, Niemeyer, literatura brasileña, literatura contemporánea, vida, ecocrítica, fin del mundo, estética y política, materialidad, monumentalidad.

This article analyzes Brazilian writer and art critique Teixeira Coelho Neto's novel sequence Niemeyer, um romance (1994); Historia Natural da ditadura (2006), O homem que vive, uma jornada sentimental (2010) and Colosso (2015)-, regrouped under the name of "The Angel of History" (Walter Benjamin), in which an apocalyptic vision of the end of the world intertwines with a meditation about life, politics, art and literature. It argues that the novel's catastrophic imaginary is presented as structurally linked to a developmental and industrial modernization project (represented in its apex in the construction of Brasilia), in which art and literature are thought through an epistemology based in rationality, monumentality, evolutionism and aesthetic autonomy. Against this, Coelho Neto's project builds a material writing, assembled with the debris of life: a minor aesthetics of the anonymous, the remaining and waste. Contemporary literature, therefore, gains a philosophical 
status because it becomes a platform in which concepts are generated and through which it is possible to build a critical theory from a different standpoint than the one offered by modern (monumental) reason.

Key words: Teixeira Coelho Neto, Brasilia, Niemeyer, Brazilian literature, contemporary literature, life, ecocritique, end of the world, aesthetics and politics, materiality, monumentality.

Las tres últimas novelas del brasileño Teixeira Coelho Neto, Historia Natural da ditadura (2006), O homem que vive, uma jornada sentimental (2010) y Colosso (2015), comienzan con escenas apocalípticas y amenazadoras. Un viento arrasador que voltea a los paseantes en el primer caso, nieve que cubre las calles de una ciudad tropical en el segundo y un cielo tan oscuro que se confunde con las rocas del suelo, produciendo una atmósfera inquietante, en la última. Los tres comienzos están signados por catástrofes naturales que generan una sensación de desastre inminente; algo que en la última novela incluso llega a pensarse como "o cenário do fin do mundo" o "o cenário atemorizante de fim dos tempos" (Coelho Neto 2015: 9 y 15). Las tres novelas conforman, junto con otra anterior llamada Niemeyer, um romance (1994), un ciclo que Coelho Neto agrupa bajo el nombre de "El ángel de la historia”, haciendo alusión a la famosa lectura que hace Walter Benjamin del "Angelus Novus" de Klee, en donde habla del progreso como aquella fuerza histórica que deja tras de sí una única catástrofe que amontona una ruina tras otra y se las va arrojando al ángel a sus pies ${ }^{1}$.

A lo largo de las cuatro novelas, se repite una trama biográfica (que incluso parece ser autobiográfica) en la que diversos recuerdos, anécdotas y relatos íntimos dan lugar a una reflexión sobre la vida y sobre cómo contar una vida; proponiendo también una pregunta sobre las posibilidades de la literatura en el mundo contemporáneo y sobre el estatuto del mismo texto literario que se está leyendo. Este plano de memoria personal o de escritura subjetiva se entreteje con una reflexión ensayística sobre el arte, la literatura y sus vínculos con las dictaduras sudamericanas, el fascismo y lo que en las novelas se nombra -haciendo mención al filósofo italiano Giorgio Agamben- como un constante "estado de excepción" en el que hemos vivido a lo largo del siglo veinte y continuamos viviendo en el veintiuno. El protagonista -que en cada novela cambia ligeramente pero

\footnotetext{
1 "Hay un cuadro de Klee que se llama Angelus Novus. En ese cuadro se representa a un ángel que parece a punto de alejarse de algo a lo que mira fijamente. Los ojos se le ven desorbitados, tiene la boca abierta y además las alas desplegadas. Pues este aspecto deberá tener el ángel de la historia. Él ha vuelto el rostro hacia el pasado. Donde ante nosotros aparece una cadena de datos, él ve una única catástrofe que amontona incansablemente ruina tras ruina y se las va arrojando a los pies. Bien le gustaría detenerse, despertar a los muertos y recomponer lo destrozado. Pero, soplando desde el Paraíso, una tempestad se enreda en sus alas, y es tan fuerte que el ángel no puede cerrarlas. Esta tempestad lo empuja incontenible hacia el futuro, al cual vuelve la espalda mientras el cúmulo de ruinas ante él va creciencio hasta el cielo. Lo que llamamos progreso es justamente esta tempestad" (Walter Benjamin 2008: 310).
} 
manteniendo ciertas características constantes que permiten la singularización (incluso por la repetición de ciertas anécdotas de un libro al otro) - cuenta su vida personal y amorosa, recorre museos y ciudades, y analiza obras de arte discurriendo sobre sobre los modos de exhibición, la arquitectura y el diseño de los espacios urbanos. Así, la vida misma y la posibilidad de contarla, el arte y la política, se van entretejiendo y forman una narrativa que se continúa -con particularidades y matices- a lo largo de todo el ciclo. Puestas todas juntas, las novelas trazan una reflexión sobre la complicidad entre un modo de pensar lo estético por un lado y la pila de catástrofes acumuladas a las que alude Benjamin, por el otro. Los escenarios distópicos no surgen como si fueran acontecimientos azarosos o como accidentes puramente naturales, sino como síntomas de una razón histórica y, por lo tanto, como inseparables de una agencia humana. Es en este sentido que creo que debe entenderse la alusión al concepto de "historia natural" -en el título de la última de las novelas: História natural da ditadura-, por medio del cual Benjamin realiza una crítica a la naturalización del curso de los eventos históricos y a un modo de representación de estos eventos desde una perspectiva temporal cronológica y teleológica ${ }^{2}$.

En este ensayo tomaré el ciclo de novelas y los paisajes devastados y apocalípticos que en ellas se retratan para pensarlos -a la luz de la filosofía de Benjamin- en relación a un desmoronamiento de las promesas de la modernidad y de lo que Susan Buck Moors identifica como el sueño utópico del siglo veinte. De modo incluso más preciso, el imaginario catastrófico surge en las novelas vinculado a una estética monumental y a una manera específica en la cual esta monumentalidad se ha desarrollado en el contexto cultural brasileño. El gesto de iniciar el ciclo con una novela enfocada en la figura de Oscar Niemeyer, le da una centralidad tal a la arquitectura, al diseño urbano y -específicamentea la ciudad de Brasilia, que permite establecer un puente entre una estética monumental dentro del urbanismo, la arquitectura y las artes visuales, por un lado, y dentro de una cultura escrita por el otro. Es decir, la crítica a una estética monumental dentro de la cultura visual (que se inicia con Niemeyer pero incluye a lo largo de las cuatro novelas reflexiones sobre diversas obras de arte, exhibiciones, obras arquitectónicas y proyectos urbanos que no necesariamente son brasileños) y la voluntad de romper con esta estética dentro de una cultura escrita y literaria, permite asumir que existe una epistemología común a ambas prácticas estéticas ${ }^{3}$. La propuesta, entonces, implica no solo pensar en una arquitectura, diseño o arte antimonumentales, sino en encontrar un concepto diferente de producción escrita -literaria

\footnotetext{
${ }^{2}$ El concepto de "historia natural" en Benjamin es altamente complejo y el sentido con el que lo usa es cambiante. En los Pasajes se contraponen la imagen dialéctica y su temporalidad específica a la estructura lógica de la temporalidad tal como se encuentra la historiografía. Según podemos leer a través de algunos de los fragmentos de los Pasajes dedicados a esta temática, para Benjamin, aquello que se ve como progreso cuando la historia es entendida desde un punto de vista natural, resulta una catástrofe si se mira desde una perspectiva materialista: "The concept of progress must be grounded in the idea of catastrophe. That things are 'status quo' (that things just go on) is catastrophe" (N9a, 1).

${ }^{3}$ Resulta pertinente aclarar que, además de escribir novelas, Teixeira Coelho Neto es crítico de arte y ha trabajado en museos e instituciones relacionadas con las artes visuales durante toda su vida.
} 
o teórica- en el que se pueda incorporar y visibilizar los restos y las experiencias de vidas menores; una estética de lo menor. En este sentido, el proyecto de Teixeira Coelho Neto tiene características particulares en relación al contexto cultural brasileño, y específicamente a cómo el modernismo se manifestó en Brasil (y es por eso que la experiencia de Brasilia se vuelve central), pero puede -o quizás incluso, debe- pensarse más allá de este contexto y en diálogo con otros proyectos narrativos - no necesariamente brasileños, e incluso, no necesariamente latinoamericanos- en los que se realiza una búsqueda estética antimonumental y en los que, justamente, hay muchas cuestiones que tienen que ver con una demarcación cultural nacional que han perdido vigencia.

Quizás ha sido Roberto Bolaño el narrador contemporáneo que más brillantemente ha expuesto la complicidad entre alta cultura y barbarie, o entre el totalitarismo y las formas elevadas y autónomas de la estética. En este caso, la insistencia en una perspectiva arqueológica que permita retomar el curso de la historia en un sentido inverso y que se base en restos materiales o en vidas menores y anónimas para construir el relato, permiten establecer lazos con escritores muy diferentes entre sí. Pienso, por ejemplo, en una lista que incluya -de un modo altamente arbitrario y poco exahustivo- a Clarice Lispector, Mario Levrero, Sergio Chejfec, Valeria Luiselli, W.G. Sebald, Emanuelle Carrère o Alejandro Zambra. En el caso de Teixeira Coelho Neto, al agrupar las novelas bajo una interpretación benjaminiana de la historia y al darle el nombre de "ciclo" se realiza un doble movimiento: por un lado, se problematiza el estatuto mismo de los textos como novelas, se las emparenta a una escritura ensayísitica y se les da una impronta casi filosófica; pero, por el otro, al afirmarlas así y todo como novelas, se propone a la literatura como un modo de intervención crítica y se le otorga un lugar dentro del esquema de producción de conocimiento. En este ensayo no me interesa tanto buscar en esta narrativa una innovación "literaria", ni tampoco pensar su narrativa dentro del contexto de la tradición literaria nacional brasileña, sino más bien partir del ciclo de novelas para pensar sobre el lugar de la literatura contemporánea -o de la estética contemporánea- como sitio de pensamiento, de generación de conceptos y, por lo tanto, como modo de construir una teoría crítica desde un sitio ajeno al de la razón (monumental) moderna.

Frente a una visión de defensa de la autonomía estética y de una concepción evolutiva de la historia, la literatura de Teixeira Coelho Neto se pregunta cómo sobreviven los restos de la experiencia para pasar a integrar un relato de vida; o cómo estos restos de vida forman parte integral y constitutiva de una reflexión crítica y teórica. Se pregunta, entonces, cómo se escribe una reflexión crítica sin deshechar la experiencia; o cómo se escribe una vida sin crear, en el gesto de escribirla, un monumento. El concepto de vida -y el desarrollo de todas las novelas a partir de una impronta biográfica que, sin embargo, no sigue una temporalidad lineal- cobra una potencialidad política en la medida en que a través suyo se rescata lo menor, lo material, o aquello que surge a pesar de la razón en forma de derroche, de resto corporal, improductivo o de deseo, y se propone como desarticulación de una estética monumental y de una historia heroica. Pensados benjaminianiamente, entonces, estos relatos operan como historias contadas "a contrapelo" o desde el punto de vista de los "sin nombre"; de aquellos a los que la Historia ha dejado de lado. 


\section{BRASIL, PAÍS DEL FUTURO: CATÁSTROFES Y MONUMENTOS}

En Ha mundo por vir? Ensaio sobre os meios e os fins, Deborah Danovsky y Eduardo Viveiros de Castro proponen que, si bien la temática del fin del mundo siempre ha existido en todas las culturas y se ha imaginado de maneras muy variadas a lo largo de la historia, este imaginario se renovó a partir de los años noventa del siglo pasado cuando se llegó a un consenso científico sobre las transformaciones climáticas y ambientales y sobre una crisis planetaria ineludible. No sería exagerado decir que a partir de ese momento, dado que esta crisis no ha hecho más que aumentar, el imaginario del fin del mundo ha alcanzado una aceleración tal que resulta imposible no tomarlo como uno de los temas más visitados de la cultura contemporánea ${ }^{4}$. La saturación de imágenes apocalípticas que presenciamos en la vida cotidiana, muchas veces relacionadas con el cambio climático pero otras relacionadas con la pobreza e indigencia extremas, la marginalidad, las migraciones masivas, los genocidios, los femicidios, las diferentes guerras y amenazas nucleares, los avances tecnológicos y los nuevos tipos de fascismos recientemente renovados en el mundo entero, han creado lo que Ashley Dawson llama "castrophic affect": "a visceral feeling that we are not just headed toward civilizational collapse but are already in the midst of it" (Dawson 2017).

Se trata de un contexto dentro del cual Brasil adquiere una relevancia extrema, no solo por ser un país con una enorme desigualdad económica, sino porque concentra la mayor reserva natural del planeta, convirtiéndose así en un escenario clave para la discusión sobre la crisis ecológica mundial y sus figuraciones distópicas. Cantidades de obras artísticas y manifestaciones culturales de todo el mundo refieren a la selva amazónica, transcurren en ella o la toman como tema central. Sin embargo, este "catastrophic affect" y la representación de la Amazonía como sitio clave para pensar el tema del fin del mundo, se opone a una narrativa aún así persistente en la cultura brasileńa y constantemente renovada: se trata de la imagen de un Brasil con un destino manifiesto, triunfal, moderno y en plena marcha hacia un futuro promisorio. Desde el ufanismo de comienzos del siglo veinte, se ha sucedido una cantidad de libros, escritos e interpretaciones -tanto de autores nacionales como extranjeros- que consolidaron una ficción de identidad nacional definida por esta marca de grandeza. El sintagma "Brasil, país do futuro" terminó por cristalizar a mitad del siglo pasado en la obra de Stefan Zweig que lleva ese título ${ }^{5}$. A pesar de la dificultad de

\footnotetext{
${ }^{4}$ Es imposible realizar un listado exahustivo de las diferentes manifestaciones culturales relacionadas a este tópico porque van desde series masivas de televisión, películas, obras de artes visuales y literatura, hasta exhibiciones enteras dedicadas al tema, como por ejemplo, la que sucede actualmente en el CCCB (Centro de Cultura Contemporánea de Barcelona), llamada "Después del fin del mundo" (http://www.cccb.org/es/exposiciones/ ficha/despues-del-fin-del-mundo/224747).

${ }_{5}^{5}$ Desde el clásico libro del nacionalismo de comienzos de siglo veinte, Por qué me ufano do meu país (1901), de Afonso Celso, hasta nuestros días, se ha reelaborado esta idea de diferentes maneras. Aunque el sintagma "Brasil, país del futuro" quedó consagrada como si fuera de autoría de Zweig, varias obras de autores extranjeros anteriores a la suya se anticiparon con títulos similares aunque no siempre con el mismo sentido: el holandés N. R de Leeuw, Brasil, pais do futuro (1909); el alemán Heinrich Schüler, Brasil, pais do futuro (1912); y el italiano
} 
sostener una versión homogénea y monolítica, esta ficción se sostuvo con vaivenes a lo largo del siglo veinte para avanzar, ya en el presente, de modos inesperados ${ }^{6}$.

Uno de los conceptos centrales en la construcción y consolidación de esta ficción de identidad ha sido el de monumento. Francisco Foot Hardman considera que uno de los modos de producción de ilusiones colectivas unificantes, naturalizadoras del poder y homogeneizantes en Brasil -lo que él llama "fantasías de Brasil" (Foot Hardman 2004: 2) ha sido a través del concepto de monumento y de una visión monumental de la identidad nacional. Dentro de esta narrativa, Brasilia ocupa un lugar privilegiado. A través de su planificación y construcción se buscaba romper con la ciudad típica del pasado e inaugurar un tipo de diseño urbano basado en principios lógicos que permitiera salir del subdesarrollo. La visión utópica con la que se construyó esta ciudad, su arquitectura monumental y la intención de que con su construcción se produjera la unificación territorial nacional entre el sertão y el litoral comenzada en 1930, son factores que contribuyeron a cargarla simbólicamente.

En parte como un legado del modernismo canónico de los años veinte y en parte debido a una coyuntura mundial de posguerra y al auge desarrollista, la compresión de la historia cultural brasileña como una marcha racional, autónoma y evolutiva se impuso de modo hegemónico ${ }^{7}$. A lo largo de los años cincuenta, esta visión se afianzó a través de ciertas

Francesco Bianco, Brasil, país do futuro para a imigração judaica (1928). Incluso el propio Zweig reconoce que no es una idea original suya al colocar como epígrafe de su libro la descripción del país hecha en 1868 por un diplomático austríaco, el conde Prokesch-Osten, en una carta: "Um país novo, um porto magnifico, o distanciamento da mesquinha Europa, um novo horizonte político, uma terra do futuro e um passado quase desconhecido que convida o homem de estudos a fazer pesquisas, uma natuera esplêndida e o contato com ideias exóticas novas" (Zweig 1941, epígrafe).

${ }^{6}$ Hace algunos años esta imagen se actualizó cuando Brasil parecía resurgir como un fénix en el discurso político-económico mundial: Jim O’Neil, economista de Goldman Sachs, agrupó a Brasil, Rusia, India y China bajo la sigla BRIC y bajo la consideración de que estos países dominarían la economía mundial para el año 2050. En el 2009, la revista "The Economist" apuntalaba éste imaginario con una tapa que atrapaba muy bien el clisé: el famoso monumento e ícono nacional del Cristo Redententor despegando hacia el cielo como si se tratara de una nave espacial bajo el título "Brazil Takes Off" (http://www.economist.com/node/14845197).

Por otro lado, mientras estoy corrigiendo este artículo, asisto a los materiales de campaña de Jair Bolsonaro en los que se promueve la imagen de un Brasil con un destino manifiesto que debe -de la mano de este "salvador"salir de su letargo para poder cumplirse. Como se ve en unos de los videos de campaña (llamado "O gigante acordou") un gigante monumental hecho de tierra se desprende de uno de los morros característicos del paisaje postal de Rio de Janeiro (es decir, es un desperendimiento "natural" del paisaje, del territorio nacional), mientras la gente (mirando desde su posición reducida) asiste maravillada y esperanzada el nacimiento de este "mito" (la canción repite que ha llegado "el mito") que vendrá a salvar a la patria de su decadencia y a darle el futuro que se merece: "O Gigante não esta mais adormecido" dice la leyenda del video (https://www.youtube.com/ watch? $=$ =LFuzySID6Y).

${ }^{7} \mathrm{Al}$ decir que el modernismo de los años veinte concibe la historia del arte de este modo, no pretendo que ésta sea una concepción monolítica, sino más bien que fue la versión del modernismo que triunfó y se impuso como lectura hegemónica de las obras más significativas. Por supuesto que hubo también un pensamiento arqueológico y dialéctico que desdice la interpretación evolutiva. Tal es el caso de Flávio de Carvalho, por 
instancias que contribuyeron a la consagración, autonomización e internacionalización del arte y de la arquitectura brasileñas: las Bienales de Arte de São Paulo -que se inician en 1951, la creación de los museos de arte modernos (principalmente el MASP y el MAM-SP) y el auge del concretismo, la abstracción geométrica y un tipo de arte altamente industrializado ${ }^{8}$. Este proceso tuvo su punto culminante en la construcción de Brasilia. Es por esto que, como propone Adrián Gorelik "Brasilia deve ser comprendida como um dos momentos mais densos da cultura moderna” (Gorelik 2012: 154) y, en tanto proyecto en el que encarna ejemplarmente el programa estético, político y cultural propio de la modernidad, puede pensarse como un "monumento da modernidade" (Gorelik 2012: 160) 9

Renato Anelli señala que es necesario pensar este impulso a la monumentalidad de la arquitectura brasileńa moderna -anticipado en el proyecto del Ministério de Educaçáo e Saude (MES) - dentro de un contexto más amplio y complejo: el movimiento de la "New Monumentality" surgido en la arquitectura moderna a principios de los ańos cuarenta. ${ }^{10}$ Según Anelli, es posible pensar que este movimiento habría intentado desligar lo monumental a la arquitectura fascista y realizar, en cambio, una asociación con la democracia y con una arquitectura comprometida con una función social e involucrada en el uso cotidiano (Anelli 423-4). Sin embargo, el propio Anelli reconoce que, más allá las intenciones, dentro del contexto de la posguerra europea, el monumentalismo de Brasilia no podía evitar ser

ejemplo, o de un Oswald de Andrade tardío, tal como muestra Gonzalo Aguilar en Por una ciencia del vestigio errático.

${ }^{8}$ Una de las líneas más importantes e influyentes líneas del pensamiento artístico de este momento -encarnada en lo que fue el primer grupo concretista, "Ruptura", liderado por el artista Waldemar Cordeiro y altamente influenciado por el suizo Max Bill- proponía un corte absoluto con todo lo viejo y con cualquier forma de arte del pasado: naturalista, figurativista, e incluso con el arte abstracto informalista, es decir, que no correspondiera a una forma racional. Según postulaban, un tipo de arte "del pasado" no se adecuaba con la etapa industrializada del Brasil del momento. El arte se movía a través de etapas que iban siendo superadas y no había superposición entre ellas. A la fase de ese momento le correspondía un arte racional con principios claros y universales, en el que no cabía la expresión subjetiva ni afectiva. Los materiales debían ser también fríos e industriales (acrílico, esmalte, aglomerado); un arte que sería "quase design". Ver Gonzalo Aguilar 2003: 59-60; França Lourenço y Amélia Paes Vieira Reis. Design Concretista. Um estudo das relaçóes entre o design gráfico, a poesia e as artes plásticas concretas no Brasil, de 1950 a 1964. La expresión "quase design" proviene de Marcos Augusto Gonçalves (1996)

9 Gorelik señala la particularidad del modernismo brasileño en relación a los movimientos europeos y a su ruptura con el pasado: "Desse ponto de vista, a experiência do modernismo brasileiro em sua versão canônica poderia aparecer omo uma completa inversáo: a finalidade do objeto artístico teria sido, nesse caso, produzir simultaneamente um futuro e uma tradição. Deste modo, pode-se dizer que a arqutietura brasileira é 'antivanguardista': porque o problema que tinha para resolver era a ausência de história, não seu excesso"(Gorelik 2012: 160).

${ }^{10}$ Para esto es necesario referirse al manifiesto "Nine Points on Monumentality" de Sigfried Giedion, Josp Lluís y Fernand Léger de 1943, y al texto de Gideon "The Need for a New Monumentality", en el cual se basó el semniaro de la Architectural Review "In Search of a New Monumentality" celebrado en 1948, al cual Lucio Costa fue invitado. 
asociado con la arquitectura fascista y con una visión cultural autoritaria. ${ }^{11}$ Anelli traza una línea directa entre éste movimiento y la tarea que se había propuesto Lucio Costa hacía ya algunos años: involucrar y comprometer la arquitectura brasileña en la construcción de una identidad nacional. De esta manera, la monumentalidad se vuelve un elemento clave: "A interação entre operação brasileira e a formulação da nova monumentalidade é inequívoca"(Anelli 422). Así, más allá de las interpretaciones divergentes en lo que hace a la asociación o distanciamiento de este movimiento con respecto al fascismo, lo cierto es que la monumetalidad se afianzó a partir de la construcción de Brasilia como una característica nacional y contribuyó a reforzar una fantasía de grandeza y de naturalización de la identidad.

A partir de esto, podríamos preguntarnos cómo se articula el imaginario catastrófico -actualizado y exacerbado en el presente a un nivel mundial- con el de un Brasil monumental asociado a un modelo desarrollista, industrial, capitalista y extraccionista que, si bien tuvo su auge en los ańos cincuenta, resurge recurrentemente imponiendo un discurso homogeneizante y civilizatorio y encarnando en un tipo particular de estética. De alguna manera, podríamos decir que el ciclo de novelas de Teixeira Coelho Neto se hace esta pregunta; o más bien imagina escenas en las cuales estos dos imaginarios se unen de un modo estructural. En este sentido, a pesar de que no haya en la primera novela Niemeyer, um romance - escenas apocalípticas de la misma naturaleza que en las siguientes, ella toma su título del nombre del famoso arquitecto modernista brasileño y uno de los dos principales representantes -junto con Lucio Costa- de lo que fue la construcción de Brasilia. El gesto de comenzar un ciclo de novelas cuya reflexión central gira obsesivamente en torno a la exposición de una complicidad entre estética y dictadura -o estética y "estado de excepción" - con una supuesta biografía de uno de los arquitectos de Brasilia, implica hacer de la utopía modernista un tema central y ligarla estructuralmente a una visión del presente. Como el mismo Teixeira Coelho dice en una reseńa sobre las memorias de Niemeyer: "Oscar Niemeyer pertence ao grupo restrito dos que marcaram o corpo e a idéia do século 20". Y luego: "Falar sobre o país nos últimos 60 anos é falar de Niemeyer. E viceversa" (Teixeira Coelho Neto 1999) ${ }^{12}$.

El lugar que ocupa Niemeyer -y por lo tanto Brasilia- dentro de esta narrativa, debe entenderse, entonces, en relación a una crítica más amplia; es decir, no como una crítica a la arquitectura o a un proyecto urbanista $-y$ ni siquiera como algo reducido al contexto puramente brasileńo (después de todo lo ubica a Niemeyer como una marca del siglo veinte)- sino como una crítica a un proyecto general de modernización que involucra -también- un modo de entender la literatura y el pensamiento desde una epistemología basada en la racionalidad, la monumentalidad, el evolucionismo y la autonomía estética.

\footnotetext{
${ }^{11}$ Siguiendo esta misma línea argumental, Adrián Gorelik dice lo siguiente: “(...) as necesidades monumentalistas do Estado nacional-desnvolvimentista não podiam, no pós-guerra europeu, espaciar à caracterização de autoritarismo (Gorelik 2005: 415-16).

${ }^{12}$ También en Colosso -la última de las novelas del ciclo-, uno de los problemas que se plantean es cómo hacer un relato del siglo veinte y si es posible -o deseable- hacer un relato orgánico del pasado.
} 


\section{ESCENARIOS DEL FIN DEL MUNDO Y VIDAS ANTI-MONUMENTALES: LOS SIN NOMBRE}

O homem que vive. Uma jornada sentimental comienza cuando un hombre brasileño llamado Buel regresa a São Paulo luego de lo que, entendemos, fueron muchos años fuera del país. Llega con un objetivo preciso: buscar a una mujer que dejó cuando se fue, buscar a quién él llama a lo largo de la novela -a pesar de que vaya cambiando la mujer que lo encarna- "su ángel”. Pero lo que encuentra en lugar del amor -o en lugar del "ángel del amor", como lo llama- es el ángel de la historia: una imagen de São Paulo apocalíptica. Toda la ciudad está nevada y sus habitantes actúan como si fuera algo normal ${ }^{13}$. Buel, sin embargo, presiente que un desastre puede ocurrir en cualquier momento:

Vista de baixo, da calçada, a Avenida Paulista parecia um longo corredor em preto\&branco que o céu baixo, pesado, tornava paradoxalmente ainda mais alto e inexpugnável. Com dificultade, afundando a perna na neve solta, Buel caminhou até o meio da avenida (...) Dali via de modo ainda mais opressor o paredão de prédios silencioso e alto e cinza. A luminosidade poderia ser a do crepúsculo. Há crepúsculos assustadores (...). A sensação de desastre que acompanhava Buel há anos. Um dia o desastre aconteceria e seria o horror total (Coelho Neto 2010: 175).

El clima helado transforma el paisaje nacional en una suerte de reverso de sí mismo: un Brasil en blanco y negro, con nieve y crepuscular; el reverso de lo tropical. Contra todas las fantasías civilizatorias decimonónicas que veían en lo tropical una causa del atraso y la pereza brasileña, la imagen de un Brasil frío - es decir, civilizado- no resulta ni optimista ni pujante sino más bien el vaticinio de un desastre. A lo largo de la novela, estas imágenes de San Pablo se van alternando con recuerdos de ciudades, museos y galerías que Buel visita en Europa acompañado por diferentes mujeres con las que tiene relaciones amorosas y en donde encuentra recurrentes alusiones al holocausto, al fascismo, a las migraciones masivas, a las múltiples y variadas dictaduras latinoamericanas, a la pobreza y a la marginalidad. Así, la novela se narra en esta alternancia: por un lado, las catástrofes sociales y políticas del pasado y del presente -lo que en un momento llama "a sujeira do tempo" (Coelho Neto 2010: 175), aludiendo a los residuos apilados que no se terminan de limpiar-; por otro lado, la imagen de un desastre ecológico a punto de ocurrir, en lo que parece más bien una visión distópica del futuro. Al establecer un vínculo entre estas dos realidades a través de una construcción ficcional, la novela altera el tiempo cronológico pues coloca el pasado en el futuro: la imagen de lo que ya ocurrió parece darnos la visión más fiel de aquello que nos depara el porvenir. De la misma manera, los órdenes natural e histórico se mezclan y se confunden hasta llegar a ser uno y el mismo: "a sujeira do tempo"

\footnotetext{
${ }^{13}$ Sólo se ve una sensación de acostumbramiento y de naturalidad en sus habitantes, como si no pudieran ver que el desastre está ya instalado: "Como pode uma pessoa viver normalmente, sobreviver, se os ventos do paraíso sempre sopram sobre ela e se a pilha de castastrofes sempre se reacumula ao seu redor?" (Coelho Neto 2010: 149).
} 
ya no se sabe si alude a un resto material de la historia (las pilas de catástrofes apiladas) o a una suciedad climática.

Algo similar ocurre en Historia Natural da Ditadura, que comienza con un capítulo en primera persona a medio camino entre la ficción y el ensayo, en el que dos amigos visitan la tumba de Walter Benjamin en Portbou. Al llegar, el viento es tan fuerte que el narrador tiene miedo de que lo tumbe. Esto da paso a una larga reflexión sobre los efectos de los fenómenos climáticos sobre la psicología y sobre el comportamiento de las personas. Podríamos decir que resulta por lo menos curioso que de lo primero de lo que se hable al llegar al sitio en el que Benjamin se suicidó sea del viento y de cómo éste puede llevar a las personas a la locura; como si hubiera podido ser un fenómeno climático -y no el fascismo- lo que habría impulsado a Benjamin al suicidio. ${ }^{14}$ Sin embargo, este viento no debería ser leído de un modo puramente realista -aunque es sabido que se trata de una zona efectivamente ventosa y que efectivamente se ha dado en llamar "el fin del mundo"- sino también de un modo alegórico, como aquel viento que empuja al ángel de Klee en la lectura de Benjamin y que es el conductor de una fuerza histórica: el progreso.

Por otro lado, ante una perspectiva completamente apocalíptica -y si pensamos esto justamente desde un punto de vista benjaminiano- resulta necesario hacer que los escombros hablen para dar vuelta el curso del tiempo (tomar la historia a contrapelo) y construir arqueológicamente una estética (una literatura) ajena a una historia naturalizada. Bajo esta luz puede leerse la siguiente escena del capítulo de Portbou, en la cual el narrador se detiene largamente en un análisis del monumento a Benjamin hecho por Dani Karavan: "Passages". Se trata de una caja de hierro oxidado que forma un corredor estrecho incrustado en la ladera por donde se baja hacia el mar. Al entrar, el narrador se sorprende gratamente al encontrar una inversión del monumento clásico elevado hacia el cielo y, al ver, en cambio, un antimonumento: "Comentei com Alfons sobre a força da experiência: um antimonumento, um monumento virado para abaixo, um monumento enterrado, um monumento que desce às profundezas, um monumento à profundeza, um monumento à queda" (Coelho Neto 2010: 22).

Dentro de la instalación en la que el visitante debe literalmente enterrarse y descender, el narrador siente lo que él llama "la fuerza de la experiencia" y toma como souvenir un pedazo de piedra oxidada que le recuerda a otro pedazo de piedra que se había llevado del muro de Berlín, ciudad en la que Benjamin nació. Estos residuos materiales de la instalación y de la vida misma de Benjamin sirven como imagen para pensar el modo en el que se va armando el relato, que más que dar cuenta de una memoria sólida, orgánica y monumental de la vida del narrador (o en este caso de Benjamin), va surgiendo a partir de retazos materiales o pedazos de anécdotas y de reflexiones que rompen la linealidad biográfica y se asocian a través de un montaje ${ }^{15}$. Así, frente a las afirmaciones solemnes,

\footnotetext{
14 “Os efeitos psicológicos parecíam evidentes (...) e explicáveis por uma alteração nos neurotransimissores cerebrais sob a influência de mudanças climáticas como as provocadas por aquele vento” (Coelho Neto 2006: 17).

15 En un artículo en el que analiza História da Ditadura junto a Delírio de Damasco, de Verónica Stigger, como ejemplos de ciertas formas narrativas contemporáneas en las que el relato se despoja de una subjetividad
} 
pomposas y románticas del tipo: "Benjamin como el símbolo del perseguido político", se afirma: "já seria uma enormidade se fosse reconhecido como símbolo de sí mesmo -(...) se fosse possivel pensar, por um instante, que ele realmente havia existido e vivido uma vida, sua vida" (Coelho Neto 2006: 54).

Este mismo gesto de recuperar los restos materiales de la experiencia para construir el relato de una vida singular y anónima frente a la visión monumental se adivina también en las otras tres novelas del ciclo. En el inicio de Colosso, el narrador se encuentra con un hombre que, luego de haber presenciado el encallamiento de un navío transatlántico, quiere escribir su vida a pesar de que no sea una vida excepcional y le pide al narrador que lo haga: "Josep Marilia (...) queria que eu resgisrasse seu relato de um brasileiro anônimo entreséculos" (Coelho Neto 2015: 10). Lo curioso es que el momento en el que el episodio del navío transatlántico le produce un impacto -o un "espanto" (Coelho Neto 2015: 13) - es cuando descubre que el nombre del barco alude a la película Film socialisme, de Jean-Luc Godard; lo cual explica que se hable del episodio como "um desastre da História" (Coelho Neto 2015: 12) o "uma catástrofe" (Coelho Neto 2015: 13) en la medida en que se refiere a cierta decepción en relación a las promesas del socialismo. Frente a esta visión oscura y arrasadora -la metáfora del transatlántico encallando es bastante explícita-, se rescata el valor de lo minúsculo y de lo menor o -volviendo a aludir a Benjamin- de lo "sin nombre" (anónimo), que pasa a adquirir de esta forma un valor político.

De igual manera, $O$ homem que vive, uma jornada sentimental nos enfrenta ya desde el título con una afirmación casi tautológica y banal. Que sea justamente la vida de un hombre común -una experiencia fuera de cualquier situación extraordinaria- la que las novelas se deciden a contar explica también que la trama de Niemeyer, um romance no se centre en analizar la obra o la gran vida del arquitecto sino en la de su biógrafo -anónima e irrelevante-, cuyo proyecto más ambicioso consiste en estudiar la vida de otra persona y esperar su muerte para poder finalmente escribir y publicar su libro. A medida que el biógrafo frustrado busca contar la vida de Niemeyer, va contando la suya propia, concentrándose especialmente en las intimidades de su relación de pareja y de su separación. Se trata de un narrador que por momentos llega a ser irritante dado que no parece poder concentrarse en su objetivo principal -Niemeyer-y al mismo tiempo no deja de hablar obsesivamente de esta imposibilidad, llevando de esta manera una vida a la sombra del gran arquitecto. A lo largo de la novela se van reproduciendo estas presencias sombrías o desajustes de una y mil formas. Primero, como un desfasaje entre la escritura y la vida, o más bien como una constatación de la imposibilidad de reproducir -a través de la escritura- la experiencia de vida. En segundo lugar, el narrador reflexiona constantemente sobre una distancia insalvable

individual para aprehender una vida anónima e impersonal, Florencia Garramuño dice lo siguiente sobre História da Ditadura: "Essa vida pessoal só se exibe em pedaços soltos, descosturados. As frases, que se desdobram en seu interior, vão proliferando, abrindo-se a outros eventos acontecidos em outros tempos e outras situaçóes e contextos" (Garramuño 2017: 104). Es decir, a pesar de que su lectura apunta hacia otra dirección que la que estoy explorando acá, ella encuentra este mismo rasgo narrativo al que me estoy refiriendo en cuanto a la capacidad del texto de hacer estallar la organicidad de una memoria biográfica (o individual). 
entre lo que se busca en el amor y lo que en él se encuentra efectivamente; y entre las intenciones y los actos (lapsus). En tercer lugar, toda la novela abunda en una suerte de falla en la precisión temporal: llegadas anticipadas, llegadas tardes y jet-lags que generan todo tipo de malentendidos. Finalmente, hay una distancia insalvable entre una "corrección" o una racionalidad buscada en la arquitectura y en el arte y lo que realmente se logra construir a través de ellos.

Frente a la imposibilidad de armar un relato total, exhaustivo y orgánico en el que los desfasajes no ocurran, lo que resta son justamente jirones que llegan de modo fragmentado e inconexo ${ }^{16}$. En $O$ homem que vive... este procedimiento se vuelve una arqueología, ya que -al igual que con los trozos de piedras oxidadas que se recogen en el anti-monumento a Benjamin- el narrador de esta novela, en su llegada al Sáo Paulo nevado, se propone coleccionar las imágenes de felicidad de su vida, y es así que se va construyendo el relato: como una suerte de montaje en el que se alternan las imágenes apocalípticas y distópicas del San Pablo crepuscular, y los recuerdos (felices) sobre viajes y visitas a ciudades, museos y galerías que, sin embargo, aluden a la pila de catástrofes históricas.

\section{LA LiTERATURA DEL FUTURO}

Hacia el final de História natural da dictadura, en el capítulo que conforma una especie de libro aparte llamado "Teoria da tristeza", el personaje principal cuenta su exilio en París junto a su compañera durante la dictadura brasileña. Frente a cierto discurso propio de la época sobre el imperativo de realizar un arte comprometido, el narrador cita a Italo Calvino y sus Seis propuestas para el próximo milenio y comienza a reflexionar sobre una parte de ese ensayo titulado "Elogio a la levedad" en el que Calvino reivindica la levedad como algo deseable para la literatura del futuro. A modo de un capítulo faltante en el libro de Calvino, el narrador de esta novela suma el amor a la levedad: "para que a literatura abriesse espaço para o amor naquele que quase sem sombra de dúvida se transforma no mais negro século da história desse bicho humano"(Coelho Neto 2006: 249). De esta manera, uno de los apartados siguientes se llama "Elogio ao amor" y en él se relatan los viajes y recorridos del narrador, visitando museos, obras de arte y ciudades junto a su compañera, de tal manera que el amor sexual se transforma en amor espiritual: "O elogio à leveza que logo se transformo em elogio ao amor, primero ao amor físico e em seguida ao amor pela arte, depois transfirugrou-se em amor pelas cidades" (Coelho Neto 2015: 252).

Podríamos decir que este último capítulo de la segunda novela del ciclo sirve como puntapié inicial de la que le sigue $-O$ homem que vive-, en donde se continúa con esta narrativa. La colección de imágenes de felicidad que el protagonista emprende al comienzo

\footnotetext{
${ }^{16}$ En una artículo reciente, Karl Erik Schollhammer propone que la estructura "anacrónica, descontínua e descentrada" de História da Ditadura es uno de los temas del libro y que el "movimiento proliferativo" (Schollhammer 2015: 46) en el que incurre, desafía cierta lógica temporal y narrativa. Esta lectura -que es sobre una sola de las novelas del ciclo- podría muy bien ampliarse al ciclo completo.
} 
de esta tercera novela son justamente estos relatos de viaje con compañeras amorosas que van variando, pero con las cuales siempre se viven experiencias de placer y hedonismo relacionadas con el arte: el protagonista no se preocupa por la subsitencia diaria (no se nombra ningún trabajo), duerme en hoteles, come en restaurantes y toma champagne en el desayuno. Se trata, por lo tanto, de una vida bohemia, ociosa y lujosa, cuya única ocupación constante parece ser la de ver arte y deleitarse con los placeres del sexo. Frente al control de la razón instrumental moderna, y frente a una estética monumental, la leveza y el amor pueden leerse como hendijas de luz en la visión apocalíptica del presente.

En una reseña sobre las memorias reales de Niemeyer, Teixeira Coelho Neto (esta vez en su papel de crítico) le reclama al arquitecto que en la narración de sus memorias no mezcle la obra y la vida, y que -aunque diga lo contrario- no le otorgue a esta última ninguna supremacía: "O Arquiteto surge, a essa luz, como um anti-romântico extremado: não quis fundir e confundir a arte com a vida" (Coelho Neto 1999). Este énfasis en la autonomía de la obra excluiría recurrentemente algo del orden de lo incierto, de lo imprevisto y desarreglado, ausencia que también ocurriría en su arquitectura. Con respecto a esto, en esta reseńa, Teixeira Coelho Neto se refiere al proyecto del sambódromo de Rio:

Teria sido interessante conhecer suas reflexões sobre essa recorrente tragédia envolvendo a arquitetura, o arquiteto e a sociedade. Ou sobre o modo como encara aquilo que parecem incongruências filosóficas entre seu pensamento e sua obra, como a ordenação do carnaval por meio de uma arquitetura que, no sambódromo do Rio, impóe à festa um espaço projetado, começo certo, duraçáo estipulada, comportamento padronizado e fim predeterminado. Mas, tampouco esta lhe parece uma questão a discutir (Coelho Neto 1999).

Darle un orden disciplinario al carnaval es, quizás, la metáfora que resume de manera más paradigmática la exclusión de la vida y de todo resto menor o improductivo dentro de una estética monumental.

En Supervivencia de las luciérnagas, George Didi-Huberman retoma una metáfora que Pasolini había utilizado para referirse a ciertos momentos fugaces de amistad, felicidad y deseo sexual ligados a un deseo artístico y a una resistencia frente al fascismo: las luciérnagas que danzan en la noche y se iluminan de un modo intermitente con un deseo de formar comunidad (Didi-Huberman 2012: 55). Didi-Huberman cita una carta de Pasolini en donde se entiende el valor que le atribuye a las luciérnagas, en tanto iluminación y esperanza frente a la oscuridad del fascismo. En su carta, Pasolini une el amor y la amistad con el arte y la poesía y les da un valor disidente: "He visto (y me veo a mí mismo también) a jóvenes hablar de Cézanne, y se podría tener la impresión de que hablaban de sus aventuras amorosas, con los ojos brillantes y turbados" (Didi-Huberman 2012: 15). Pero en los ańos setenta, Pasolini sentencia la muerte de las luciérnagas frente a lo que él considera como instauración de una forma cultural en la que ya no hay espacio para estos resplandores. La mirada apocalíptica de Pasolini en su declaración de la muerte de las luciérnagas - 
sostiene Didi-Huberman — "es justamente dar crédito a lo que la máquina [totalitaria] nos quiere hacer creer. [...] es estar convencidos de que la máquina cumple su trabajo sin resto ni resistencia. Es no ver el espacio —aunque este sea intersticial, intermitente, nómade, situado en lo improbable - de las aperturas, de los posibles, de aquello que surge a pesar de todo" (Didi-Huberman 2012: 42).

En el proyecto narrativo de Teixeira Coelho esta colección de momentos hedonistas representan -como las luciérnagas de Pasolini- un modo de resistir a la pila de catástrofes del ángel de la historia. Es por eso que "el ángel del amor" (como denomina a las mujeres que lo acompañan en estas escenas) funda una estética de la leveza, de lo anónimo, del derroche, de lo material y de la vida: una estética alternativa a la monumental, evolutiva y autónoma. Es aquí que cobra sentido que Teixeira Coelho Neto articule su proyecto crítico bajo una forma literaria y apelando a la ficción. Ante la posibilidad de escribir un ensayo fundamentado racional, orgánica y argumentativamente para hablar de las contradicciones del proyecto utópico moderno, elige utilizar una escritura que, como la vida, evite un evolucionismo e incluya jet-lags, lapsus e intermitencias. La literatura se escapa al ritmo de la historia, y trae un resto improductivo, inclasificable, desordenado y ajeno a una razón práctica e instrumental. En relación a esto aparece la felicidad, sin ningún tipo de propuesta didáctica y bienpensante, sin ninguna corrección política. Si este rescate es político, solamente lo es en lo que hay de político en lo erótico, en lo ocioso, en lo inutil y en el despilfarro; en aquel sitio en el que -como ocurre con las luciérnagas de Pasolini- lo poltíco encarna en los cuerpos: puro gasto o deshecho, algo menor y anti-monumental.

\section{OBRas Citadas}

Aguilar, Gonzalo. 2003. Poesía Concreta Brasileña. Las vanguardias en la encrucijada modernista. Rosario: Beatriz Viterbo Editora. . 2010. Por una ciencia del vestigio errático. Buenos Aires: Grumo.

Anelli, Renato. 2012. "Nova monumentalidade e integração das artes no Brasil. Do Ministério a Brasília”. En: Xavier, Alberto \& Julio Katinsky (Orgs.) Brasília. Antología Crítica. São Paulo: Cosac\&Naify. 420-426.

Benjamin, Walter. 2008. Sobre el concepto de historia. En Obras, libro I, Vol.2. Madrid: Abada Editores. 304-318. 2015 [2002]. The Arcades Project. Cambridge: Harvard University Press.

Coelho Neto, Teixeira. 2015. Colosso. São Paulo: Iluminuras. . 2010. O homem que vive. Uma jornada sentimental. São Paulo: Iluminuras. . 2006. História Natural da Ditadura. São Paulo: Iluminuras. . 1999. "Confisão em meias palavras”. Folha de São Paulo 17/1/1999.

(http://www1.folha.uol.com.br/fsp/mais/fs17019910.htm) . 1994. Niemeyer: um romance. São Paulo: Geração Editorial.

Danovsky, Deborah \& Eduardo Viveiros de Castro. 2014. Ha mundo por vir? Ensaio sobre 
os meios e os fins. Desterro, Florianopolis: Cultura e Barbárie Editora.

Dawson, Ashley. 2017. Extreme cities. The Peril and Promise of Urban Life in the age of Climate change. London: Verso.

Didi-Huberman, Georges. 2012. Supervivencia de las luciérnagas. Madrid: Abada.

França Lourenço, Maria Cecília. 1999. Museus Acolhem o Moderno. São Paulo: Editora da Universidade de São Paulo.

Foot Hardman, Francisco. 2004. "Pontos extremos. Ruinas invisíveis nas Fronteiras de um País". Visiting Resource Professor Papers. Austin, Texas: LLILAS, University of Texas. (https://repositories.lib.utexas.edu/handle/2152/4073)

Garramuño, Florencia. 2017. "Depois do sujeito: formas narrativas contemporâneas e vida impessoal." Estudos de literatura brasileira contemporânea 50: 102-111.

Gorelik, Adrián. 2012. "Brasília: Museu da Modernidade". En: Xavier, Alberto \& Julio Katinsky (Orgs.) Brasília. Antología Crítica. São Paulo: Cosac\&Naify. 411-419. . 2005. Das vanguardas a Brasilia. Cultura Urbana e Arquitetura na América Latina. Belo Horizonte: Editora UFMG.

Karl Erik Schollhammer. 2015." A Hitória Natural da Ditadura”. Lua Nova 96: 39-54.

Zweig, Stefan. 1941. Brasil, pais do futuro. Rio de Janeiro: Editora Guanabara. 
